\title{
STUDY ON QUANTITATIVE SPECIATION, BY BCR METHOD, OF ZINC CONTENT FROM RIVER SEDIMENTS
}

\author{
Georgiana Vasile*, Stanescu Bogdan, Tudor Claudia, Elena Mihaila \\ National Research and Development Institute for Industrial Ecology - ECOIND 90-92 Panduri Road, 050663, \\ Bucharest, sector 5, Romania \\ *Corresponding author: phone: +40/21/4100377; fax:+40/21/4100575; e-mail: ecoind@incdecoind.ro
}

Keywords: sediment, sequential extraction, bioavailability, zinc mobility

Anunwanted consequence of human activity and of uncontrolled industrialization is the environment contamination with a lot of pollutants, among them heavy metal anthropogenic pollution having some most serious consequences. A reliable estimation of pollution level is made by studying heavy metal concentrations in the sediments.

In our study the zinc content of the water and river sediments has been investigated, in an area polluted by mining activities, to provide information on the mobility and availability of this element. Sediment and water samples have been collected from significant sites in a former mining area in which with some sterile pits, which represent a major environmental hazard.

The zinc mobility and bioavailability in the environment was investigated by the three-step sequential extraction procedure, a protocol proposed by the Standards, Measurements and Testing programme (SM \& T-formerly BCR) of the European Union. The BCR sequential extraction scheme has the advantage that there are reference materials available with certified and indicative values for the concentrations of selected elements in the particular extraction steps. The BCR procedure enables fractionalization of metal content into the following fractions:

- EASILY MOBILIZABLE FRACTION: This fraction contains the specifically bound, surface occluded species (sometimes also $\mathrm{CaCO} 3$ bound species and metallo-organic complexes with low bonding forces).

- ORGANICALLY BOUND FRACTION

- Mn-Fe-and Al-OXIDE BOUND FRACTION

- RESIDUAL FRACTION: This fraction mainly contains crystalline-bound trace metals and is most commonly dissolved with high concentrated acids and special digestion procedures.

Combination of data from sequential extraction procedures and normalisation approaches provides a good basis to estimate the proportions of the easily and sparingly soluble metal fractions in the samples investigated and to identify the anthropogenic input of metals into the environment.

\section{Introduction}

From the pollution types that are to be found in our country, the most prevalent and having powerful effects for the quality of surface waters and of the sediments, is the heavy metals pollution that is to be found especially in the areas having a long ores extraction activity.

Understanding the importance of sediments role in contaminants transport and storage, conduced to an increasing preoccupation of the researchers and of the organisms responsible for the control and the prevention of water pollution, in the pollutant compounds knowledge field.

For an evaluation of heavy metals charge in the sediments, is not sufficient to determinate their total concentration. The establishment of the metals proportions in easy soluble fractions and in the hard soluble ones is very important.

These fractions evaluation allows the elucidation of their existing dangers and seriousness for the aquatic ecosystems [1].

The signification of speciation analyze as a method for estimating the environment risk was recognized by the Environment Conservation Council from Australia and New Zeeland (ANEZECC), who recommanded the examination of bioaccesible concentrations, where the metals total levels overpass the levels established into the Interimare Quality Criteria for Sediments[2].

For the estimation of the natural and the anthropogenic inputs of the heavy metals in the sediments, are used identification methods by sequential chemical extraction (BCR technique) and normalizations, based on the correlations between the concentrations of the elements present in the tracks, and an element that is naturally present in the investigated environment [3].

Further on are presented the results of the researches effectuated on sediments sampled from Certej River, which is affected by the long ore extraction activities. The papers that present the results in the thematic approach were directed towards zinc content knowledge and towards the quantification of its existing forms in sediments. 


\section{Experimental part}

\section{Study area}

The studied Certej River sector is placed on the territory of Certej village, Hunedoara district almost $20 \mathrm{~km}$ to Deva, on north direction.

This river sector, named Baiaga Valley, is spreading on a $1 \mathrm{~km}$ distance between the confluence with Bocsa Mare (Coranda) River and the confluence with Bocsa Mica (Ciongani) River. This rivers tributary to Certej Valley bring a significant contribution of heavy metals pollution, taking into account the fact that in the area between the rivers, on their valleys and also in Baiaga Valley sector, are placed objectives belonging to some mining exploitations having the precious metals extraction activity field. These objectives are represented by open exploitations, underground exploitations and by wastes deposits afferent to them - dumps.

\section{Sampling}

The investigations objective was to establish the quality of the sediments of Baiaga River (Certej) upstream and downstream the objectives that generate pollution as a consequence of the activity unrolled in the area, in order to put in bold line a possible accumulation of the pollutants from the water, in the sediments.

In order to effectuate the experiments the sediments were collected along Baiaga River sector (samples 1-7) and on its affluent (Coranda River, Nicodim gallery, Ciongani River and quarry water) (samples 8-10) presented in figure 1. The samples were collected from the upper layer of the sediment, along with the surrounding water, in order to estimate the natural substance of the studied analytes.

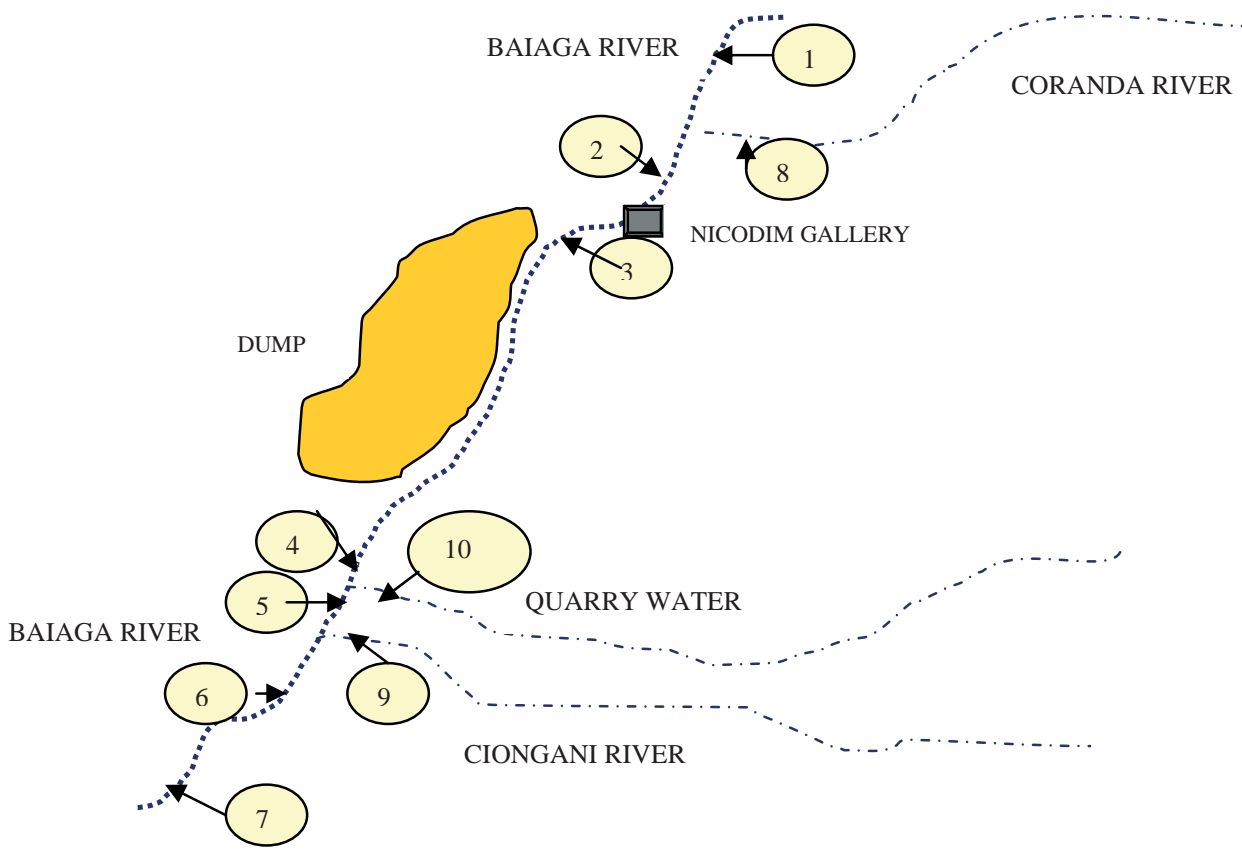

Fig. 1. Sampling sites of the investigated area

\section{Equipment}

Metals concentrations were determined by atomic absorption spectrophotometer in flame, to a Nova A 300 instrument (Analytik Jena , Germany), in air- acetylene flame.

Zinc extraction from the sediment by the sequential extraction procedure was realized in 50 ml polyethylene tubes. A mechanical shaker was used for samples shaking. Sediment extracts were whizzed to a Rotofix 32 centrifuge (Hettich, Germany) to 2200 rpm for $20 \mathrm{~min}$.

\section{$\underline{\text { Reagents }}$}

Zinc standard solution was used (1000 $\left.\pm 2 \mathrm{mg} \mathrm{dm}^{-3}\right)$ in $5 \% \mathrm{HNO}_{3}$. Work standardization solutions used for calibration in analyzing the samples from the sequential extraction, were daily prepared by diluting storage solution with extraction solution. The extractors used in the three extraction steps are: $0,11 \mathrm{M}$ acetic acid; 0,5 M hydroxyl ammonium chloride; $1 \mathrm{M}$ ammonium acetate.

The scheme of the sequential extraction method, as it was applied in the study is presented in fig.2. 


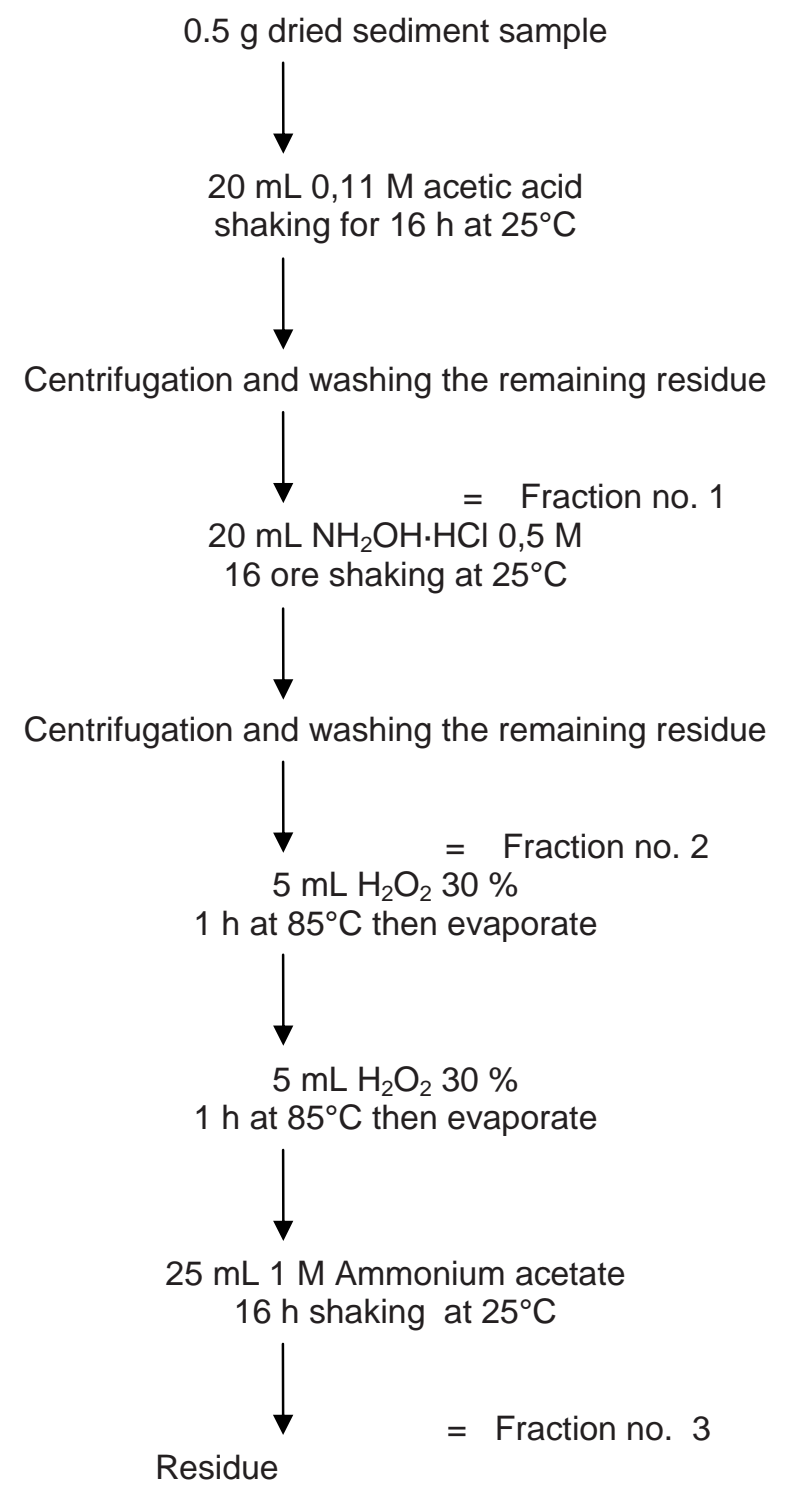

Fig. 2 BCR Sequential Extraction Scheme

Work method

In the first step of the scheme are set free the metals connected to carbonates and the ones from the changed fraction. In the second step, are leached the metals connected to iron and manganese amorphous oxides and hydroxides. In the third step $_{2} \mathrm{O}_{2} 30 \%$ oxidation, stabilized with acid and $1 \mathrm{M}$ ammonium acetate extraction, $\mathrm{pH}$ 2, adjusted with nitric acid ) are separated the metals connected to the organic matter and the sulfates.

The sequential extraction of the heavy metals from the sediment was realized using o,5 g sediment in which was added in a $20 \mathrm{ml}$ whizzing tube, $0,11 \mathrm{M}$ acetic acid. The tube was shaken by rotating it to $30 \mathrm{rpm}$ for 16 hours with a shaker, and then they were whizzed to 2200 rpm for 20 minutes.

The supernatant was passed into $25 \mathrm{ml}$ glass bottles. Then over the sediment in the tubes were added $10 \mathrm{ml}$ bidistilled water. The tubes were shacked for 15 minutes, whizzed, and the supernatant was eliminated.

In each tube was added $20 \mathrm{ml}$ 0,5 M hydroxylamine chlorine hydrate, $\mathrm{pH}=2$ repeating the shaking, whizzing and washing process.

In the third step in each tube was added $5 \mathrm{ml}$ hydrogen peroxide, the tubes were closed untied on room temperature for an hour and then they were kept on the water bath to $85^{\circ} \mathrm{C}$ for another hour.

The tubes were opened and hydrogen peroxide was evaporated, the volume being reduced to almost $1 \mathrm{ml}$. a additional quantity of $5 \mathrm{ml}$ hydrogen peroxide was added and the tubes wee closed and kept on the water bath for an 
hour. Hydrogen peroxide was evaporated than almost close to dry. After cooling, $25 \mathrm{ml} 1 \mathrm{M}$ ammonium acetate was added (acidulated to $\mathrm{pH} 2$ with HNO3) repeating the shaking, whizzing and washing.

\section{Results and discussions}

The determination of metal total concentration from sediments

In order to evaluate zinc charge, total concentrations were determinated and it was observed that in all the sediments except the first one, which is situated upstream the objectives that generates pollution as a consequence of the activity deruled in the area, zinc concentrations overpassed the limit value (150 mg kg-1 d.w.) established by Romania's legislation for zinc in sediments [4].

Table 1

Total concentrations of zinc (mg/kg d.w.) in river sediments determined within FAAS

\begin{tabular}{|c|c|c|}
\hline Sample name & Sample location & $\begin{array}{c}\text { Zn Concentration } \\
\text { (mg/kg d.w.) }\end{array}$ \\
\hline 1 & Baiaga River & 134,8 \\
\hline 2 & Baiaga River & 366,38 \\
\hline 3 & Baiaga River & 389,6 \\
\hline 4 & Baiaga River & 381,74 \\
\hline 5 & Baiaga River & 715,85 \\
\hline 6 & Baiaga River & 432,3 \\
\hline 7 & Paraul Baiaga & 387,6 \\
\hline 8 & Coranda River & 680,8 \\
\hline 9 & Ciongani River & 494,68 \\
\hline 10 & Quarry water & 494,75 \\
\hline
\end{tabular}

\section{Zinc partitioning in sediments}

Because only a part of the total quantity of heavy metals from the sediments can be considered bioaccesible, labile, mobile and potentially toxic for the environment, the total concentrations of metals are not enough for the estimation of heavy metals pollution stat. This is the reason for which it was made the study of zinc partitioning in the sediments by applying BCR extraction procedure[5-7].

This procedure allows zinc concentrations partition into the following fractions:

- Easy soluble fraction: this fraction contains the metal connected to carbonates or absorbed to the surface and metallic-organic complexes in which the metal in weakly connected.

- The fraction connected to iron or manganese oxides

- The fraction connected to organic combinations

Zinc concentrations from 1-3 steps were summed and compared to the total concentration. The results referring to zinc partition in the sediments from the mining area are presented in figure 3.

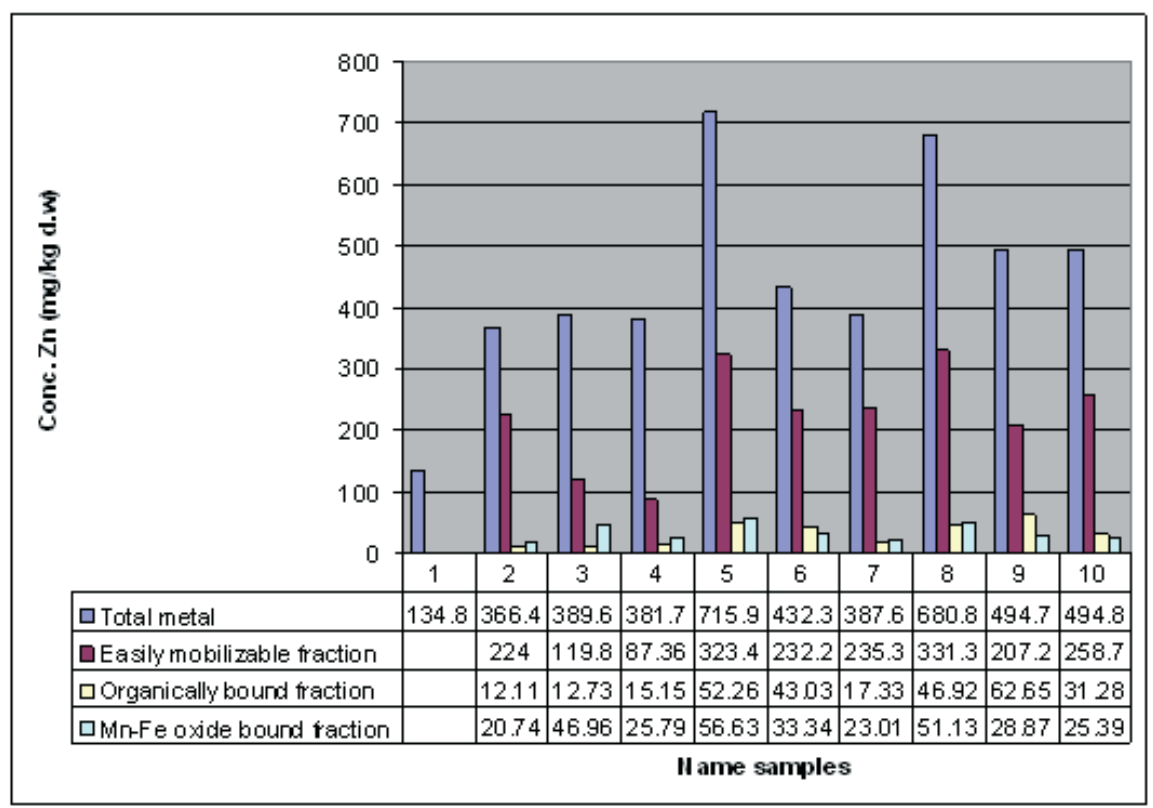

Fig. 3. Partitioning of Zn in river sediments 
The dates from figure 3 indicate that in the analyzed samples $20-80 \%$ of zinc exists as easy soluble fractions, $5-20 \%$ of zinc is connected in organic combinations and 3-20\% represents zinc fraction connected to the iron and manganese oxides and hydroxides.

\section{Normalization process}

This process allows aluminum use, a major constituent of aluminosilicates or iron use, a clay pointing constituent.

In order to evaluate iron and aluminum as candidates for establishing the normalization factors, were determined the total concentrations of these elements. The correlation between iron concentration and aluminum concentration should be linear if the two elements come from natural environment. Because of the mining activities, for iron content is very high for the analyzed samples (5-10 \% d.w.) comparing to the aluminum content (0,1-0,3\% d.w.) which indicates the fact that it does not exist a linear dependence between the concentrations of these metals. Because of these reason it wasn't allowed iron use as a normalization factor, aluminum being choose in this scope, because it was considered that it comes from the natural environment.

In order to establish the natural and the anthropogenic inputs in zinc sediments, the total concentrations of this element were correlated with aluminum concentration in the same sediment sample.

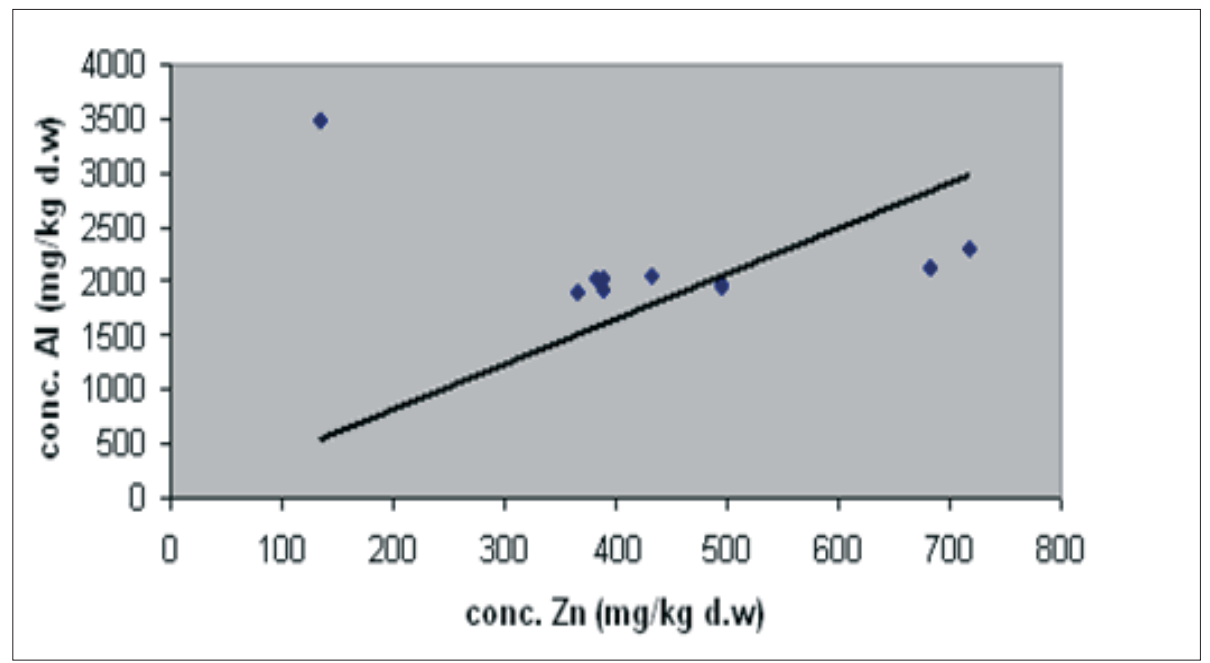

Fig.4. Relationships of $\mathrm{Zn}$ with $\mathrm{Al}$ in sediments

In figure 4 it can be seen that, in the investigated sediments case does not exist a linear dependence of zinc concentrations to aluminum concentration, which indicates the anthropogenic origin of this element because of the mining activities.

\section{Conclusions}

Within both methods it was putted into bold line the fact that zinc content induced in the system and accumulated in sediments from the pollution sources generated by mining activities unrolled in the area.

Sequential method allowed the quantification of accessible fraction and therefore able to generate impact to the aquatic ecosystems, and the aluminium normalization method confirmed the existence of a zinc content over passing the concentrations of the natural environment.

\section{References}

[1] SVETE, P. R., MilAC, PIHLAR, B., Ann. Chim. (Rome), 90, 2000, p. 323.

[2] ANZECC, Guidelines for Fresh and Marine Water Quality, 2000.

[3] DASKALAKIS, D.K., O’CONNOR, T.P., Environ. Sci. Technol., 29, 1995, p. 470

[4] Ordin nr.161/2006 pentru aprobarea Normativului privind clasificarea calitatii apelor de suprafata in vederea stabilirii starii ecologice a corpurilor de apa. 
[5] QUEVAUVILlER, Ph., RAURET, G.J., LO’PEZ-SANCHEZ, F., RUBIO, R.A., URE, MUNTAU, H., Sci. Total Environ., 205,1997, p. 223.

[6] RAURET, G.J., LO’PEZ-SANCHEZ, F.A., SAHIQUILLO, RUBIO, R.C., DAVIDSON, URE, A., QUEVAUVILLER, Ph., J. Environ. Monit., 1,1999, p. 57.

[7] RAURET, G.J., LO’PEZ-SANCHEZ, F.A., SAHIQUILLO, BARAHONA, E.M., LACHICA, URE, A.M., DAVIDSON, C.M., GOMEZ, A.D., LU“CK, BACON, J.M., YLI-HALLA, MUNTAU, H., QUEVAUVILLER, Ph., J. Environ. Monit., 2, 2000, p. 228. 